\title{
DIELECTRIC STUDY OF LITHIUM AND SODIUM BOROPHOSPHATE GLASSES
}

Ionic conductivity and dielectric properties such as dielectric permittivity and loss tangent for the samples of lithium and sodium borophosphate glasses were investigated using the electrical conductivity measurements in the range of frequency from $10 \mathrm{~Hz}$ to $2 \mathrm{MHz}$ and various temperatures below $T_{g}$. The measured data of ac conductivity were described according Jonscher's power law and experimental values of imaginary part of electric modulus were fitted by $K W W$ function. From the fitted parameters, the activation energies for conduction and relaxation time were found which characterize the hopping processes and transport mechanism in these ion conducting glasses.

Keywords: Borophosphate glasses, ionic conduction, dielectric properties, electric modulus formalism, relaxation time.

\section{Introduction}

Borophosphate glasses may find potential use in different technological applications. They are suitable as host materials in laser applications, solar energy converters or electrode materials in Li secondary batteries [1]. However, the biggest demand of their possible usage is for the developing of solid state electrolytes [2, 3]. Next-generation of battery for electronic devices e.g. electrical vehicle, energy storage systems or smart phones, have to possess high energy density, low cost and stable interface between the interphase of the electrodes and electrolyte [4] Especially for the intercorpotation of Li metal into secondary batteries, it is important to avoid dendrite formation which may lead to safety problems due to possible shortcircuiting [5]. So, the developing of the stable interface is the biggest issue for the solid state electrolyte materials. These glasses have shown to be promising candidates for improved electrolytes of Li-ion batteries due to their physical properties than high ionic conductivity at room temperature (about $10^{-7} \mathrm{~S} / \mathrm{cm}$ ), chemical stability and compatibility with the electrode materials [4-6]. The maitanance of stable interface between electrode and electrolyte requires the precise reproduction of components which is based on the good knowledge of physical properties.

From the review of literature we can see several spectroscopy studies such as Raman spectroscopy, X-ray photoelectron spectroscopy or Nuclear Magnetic Resonance which are focused on the relationship between the structural changes and physical properties in alkali borophosphate glasses $[6,8,9]$. The choise of this system is often used for theoretical interest as a model sample for studies of the mixed glass former effect (MGF). The MGF describes the change in ionic conductivity in glasses which can be revealed as decrease or increase in the ionic conductivity with the change of the glass forming oxides while keeping the modifier oxide content constant $[2,3,8]$.

As Jonscher has shown in [10] there are wide-reaching similarities between the electrical and mechanical response of system, also shown in [11], although only partially understood. So, this paper represents the first stage of our investigation aiming to compare the electrical and mechanical response of ionic conducting systems Na-B-PO and Li-B-PO. In this paper we present the conductivity and dielectric measurements of glasses of the systems with composition $50 \mathrm{R}_{2} \mathrm{O}-\mathrm{xB}_{2} \mathrm{O}_{3}-(50-\mathrm{x}) \mathrm{P}_{2} \mathrm{O}_{5}(\mathrm{R}=\mathrm{Li}$ or $\mathrm{Na}$ ), which are analyzed by several formalisms.

\section{Experimental part}

The lithium and sodium borophosphate glasses of the systems of composition $50 \mathrm{Li}_{2} \mathrm{O}-\mathrm{xB}_{2} \mathrm{O}_{3}-(50-\mathrm{x}) \mathrm{P}_{2} \mathrm{O}_{5}$ and $50 \mathrm{Na}_{2} \mathrm{O}-\mathrm{xB}_{2} \mathrm{O}_{3}-(50-\mathrm{x}) \mathrm{P}_{2} \mathrm{O}_{5}$ were prepared by the melting and quenching method. Glass batches were obtained through mixing reagent grade raw materials, $\mathrm{Li}_{2} \mathrm{CO}_{3}$ and $\mathrm{Na}_{2} \mathrm{CO}_{3}$ (Sharlau, ACS), $\mathrm{B}_{2} \mathrm{O}_{3}$ (Panreac) and $\left(\mathrm{NH}_{4}\right)_{2} \mathrm{HPO}_{4}$ (Sharlau, ACS), which were calcined in porcelain crucibles up to $450{ }^{\circ} \mathrm{C}$ in an electric furnace and then melted during $2 \mathrm{~h}$ at temperatures ranging from $800{ }^{\circ} \mathrm{C}$ to $1000{ }^{\circ} \mathrm{C}$ depending on their composition. The melts were

\footnotetext{
* ${ }^{1}$ Jana Mizerakova, ${ }^{1}$ Peter Hockicko, ${ }^{2}$ Francisco Munoz

${ }^{1}$ Department of Physics, Faculty of Electrical Engineering, University of Zilina, Slovakia

${ }^{2}$ Ceramics and Glass Institute (CSIC), Kelsen, Madrid, Spain

E-mail: hockicko@fyzika.uniza.sk
} 
poured onto brass molds and annealed above their corresponding glass transition temperature. The samples were prepared at the Ceramics and Glass Institute of the Spanish Research Council (CSIC) in Madrid, Spain.

The prepared samples were polished to be flat and planeparallel. The both sides of samples were sputtered with gold electrodes of thickness $\sim 1 \mu \mathrm{m}$.

The dielectric spectroscopy is widely used tool for the investigation of materials [12]. Spectroscopy measurements were done using LCR Meter OT 7600 Plus at frequencies in the range from $10 \mathrm{~Hz}$ to $2 \mathrm{MHz}$ (200 measurements for each of the range of temperature in steady state) for increasing temperature in the range below $T_{g}$ - transition point. We performed measurements of chosen temperatures (with time per measurements: 5 min and time per stabilization of measured system: $20 \mathrm{~min}$ ).

The evaluation of measurements were carried out by different electrical and dielectric quantities $Z^{*}(f), \sigma^{*}(f), \varepsilon^{*}(f)$ and $M^{*}(f)$ which are plotted in the both real and imaginary representation. Also, they are related through their reciprocal representation, then we can write $\sigma^{*}(f)=\sigma^{\prime}(f)+\sigma^{\prime \prime}(f)=1 / Z^{*}(f), \varepsilon^{*}(f)=\varepsilon^{\prime}(f)+\varepsilon^{\prime \prime}(f)=1 / M^{*}(f)$ and $\sigma^{*}(f)$ is described by the following equation $\sigma^{*}(f)=j \omega \varepsilon_{0} \varepsilon^{*}(f)$, where $\omega$ is the angular frequency and $\varepsilon_{0}$ is the permittivity of free space. According to the symbolic-complex method of circuit analysis we can designate the complex permittivity of the investigated material using the equation:

$\varepsilon^{\prime}=\left(\frac{C}{\varepsilon_{0}} \frac{h}{A}\right)$ and $\varepsilon^{\prime \prime}=\left(\frac{h}{\omega \varepsilon_{0} R A}\right)$

where $C$ is measured capacitance, $R$ is the value of measured resistance, $A$ denotes the area of the plates and $h$ is thickness of the sample.

\section{Results and discussion}

\subsection{Ionic conductivity}

Figure 1 shows the results of the ac conductivity measurements provided at the investigated samples which have been studied over wide ranges of frequencies and temperatures for sample $50 \mathrm{Li}_{2} \mathrm{O}$ $\mathrm{xB}_{2} \mathrm{O}_{3}-(50-\mathrm{x}) \mathrm{P}_{2} \mathrm{O}_{5}(\mathrm{x}=5 \mathrm{~mol} \%)$. Typically, the ionic conduction follows the Jonscher's power law function:

$\sigma(\omega)=\sigma_{D C}+A \omega$

where $A$ is constant related to strength polarizability, $s$ is power law exponent and $\sigma_{D C}$ is dc conductivity and corresponds to the independent frequency part at low frequency. The conductivity dependence exhibits the significant increase according with power law trend in the high frequency region. The motion of charge carried in dc region is related to the long-range diffusion of ions which are moving via activated hopping. The rate of hopping is given by Arrhenius equation:

$\sigma_{D C}=\sigma_{0} \exp \left(-\frac{E^{D C}}{k_{B} T}\right)$

where $\sigma_{0}$ is pre-exponencial factor, $E^{D C}$ is activation energy for ionic conduction, $T$ is temperature in $\mathrm{K}$ and $k_{B}$ is Boltzmann's constant. The values of $\sigma_{D C}$ were determined from the Equation 2 and used for the evaluation of the activation energy. The calculated values of activation energies for conduction are shown in Table 1.
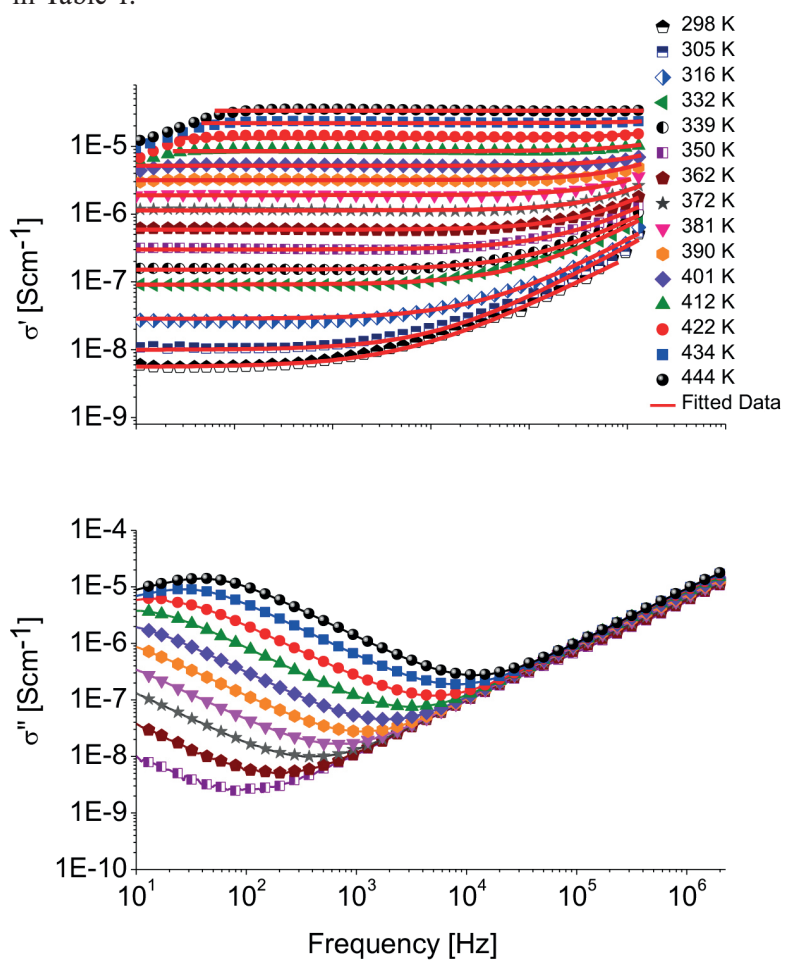

Fig. 1 Frequency dependence of real and imaginary parts of ac conductivity for glass $50 \mathrm{Li}_{2} \mathrm{O}-\mathrm{xB} \mathrm{B}_{2} \mathrm{O}_{3}(50-x) \mathrm{P}_{2} \mathrm{O}_{5}(x=5 \mathrm{~mol} \%)$.

Red lines represent theoretical fit accordance with Equation 2

Figure 2 depicts the real and imaginary parts of complex impedance where characteristic peak of $Z$ " is shifted to higher frequency with the increase of temperature. The graphical inset in the Fig. 2 represents the Nyquist diagram which is plotted as the dependence of real and imaginary part of complex impedance and the intersection of the bulk response semicircle with zero value of

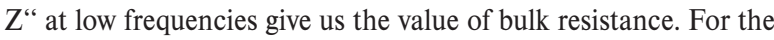
determination of the dc conductivity the following expression is used: $\sigma_{\mathrm{DC}}=\mathrm{d} /(\mathrm{RxA})$, where $d$ is diameter of sample, $A$ is area of electrodes surface and $R$ is bulk resistivity as determined from the intercept with the $\mathrm{x}$-axis in the Nyquist diagram. The calculated values of dc conductivity from Nyquist diagram were in the good agreement with evaluated values from fitted data according Jonscher's function. 

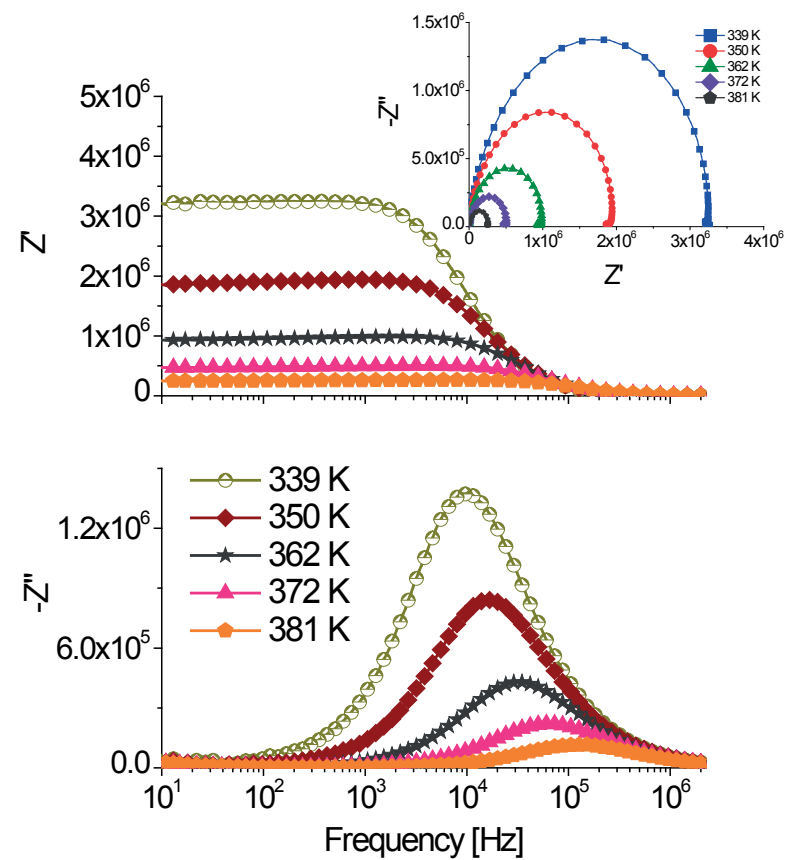

Fig. 2 Frequency dependence of real and imaginary parts the complex impedance measured at different temperatures for sample $50 \mathrm{Li}_{2} \mathrm{O}-\mathrm{xB}_{2} \mathrm{O}_{3}-(50-x) \mathrm{P}_{2} \mathrm{O}_{5}(x=5 \mathrm{~mol} \%)$.

Nyquist diagram is shown in the graphical inset for $50 \mathrm{Li}_{2} \mathrm{O}-\mathrm{xB}_{2} \mathrm{O}_{3}$ $(50-x) P_{2} O_{5}(x=5 \mathrm{~mol} \%)$ at different steady state value of temperature

\subsection{Dielectric behaviour}

For the investigation of the dielectric properties, we used two different formalisms, complex permittivity and the reciprocal approach electrical modulus. Figure 3 shows the frequency dependence of complex permittivity in $\log -\log$ scale for the temperature below $T_{g}$, for one sample with composition $50 \mathrm{Li}_{2} \mathrm{O}$ $\mathrm{xB}_{2} \mathrm{O}_{3}-(50-\mathrm{x}) \mathrm{P}_{2} \mathrm{O}_{5}(\mathrm{x}=5 \mathrm{~mol} \%)$. In the plot of frequency dependent $\varepsilon^{\prime}$, we can observe two characteristic values $\varepsilon_{\infty}^{\prime}(\omega)$ and $\varepsilon_{s}^{\prime}(\omega)$ for a material with ionic conduction. The value $\varepsilon_{\infty}^{\prime}(\omega)$ is observed in the higher range of frequencies where $\varepsilon^{\prime}$ reaches a constant value that is the result of a much rapid polarization process in material. The static value $\varepsilon_{s}^{\prime}(\omega)$ is observed in the low-frequency plateu before the appearance of electrode polarization. What is more, we can notice that plateau region shifts to higher frequency with the increase of temperature.
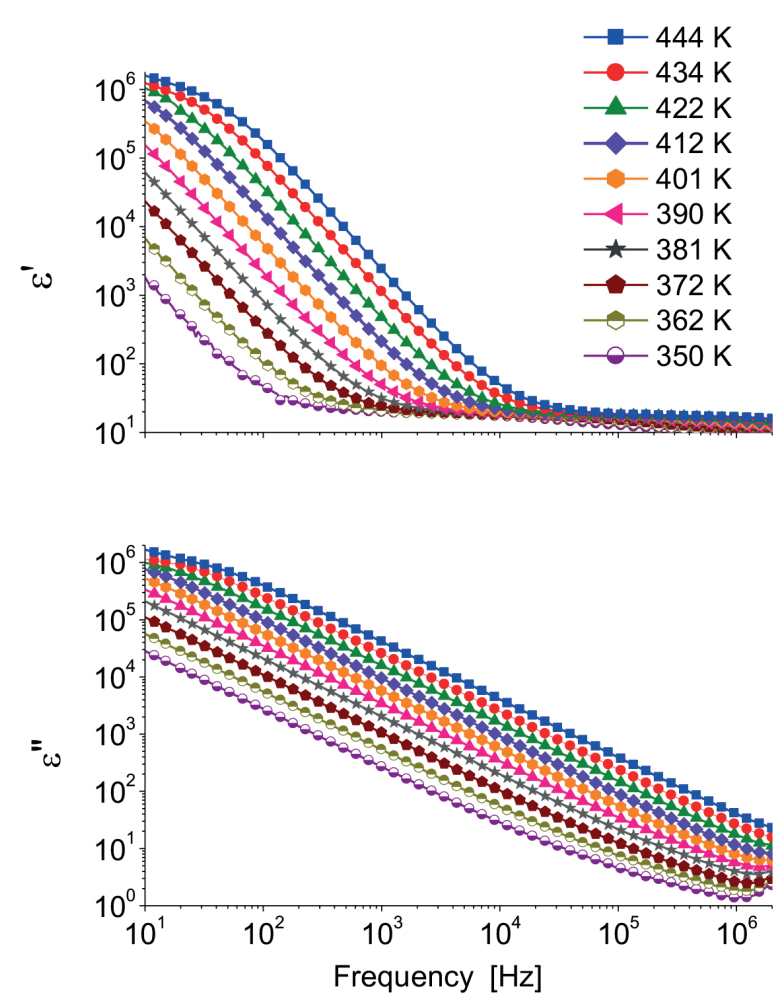

Fig. 3 Real and imaginary parts of the dielectric permittivity as a function of frequency at selected temperatures for sample $50 \mathrm{Li}_{2} \mathrm{O}-x \mathrm{~B}_{2} \mathrm{O}_{3}-(50-x) \mathrm{P}_{2} \mathrm{O}_{5}(x=5 \mathrm{~mol} \%)$

The electric modulus is related to dielectric permittivity through the expression $M^{*}=1 / \varepsilon^{*}$, and is commonly used in the investigation of relaxation phenomena for ionic conducting glasses. Figure 4 depicts the variation of imaginary and real parts of complex modulus as a function of frequency. In the imaginary part of modulus typical asymmetric peaks can be observed, which shift to higher frequencies with increasing temperature. The quantity $f_{M A X}$ is the frequency corresponding to the maximum of the modulus peak and divides the transition of mobile ions from the short range transition occurring at higher frequency part of peak to a long range in the lower frequency part of imaginary modulus peak. From the value of frequency $f_{\text {MAX }}$, we can get the conductivity relaxation time by condition $2 \pi f_{M A X}=1$. The parameters of $f_{M A X}$ are determined by fitting process with the modified KWW function suggested by Bergman [13]. According to this, the imaginary part of electric modulus may be represented as

$$
M^{\prime \prime}=\frac{M_{M A X}^{\prime \prime}}{(1-\beta)+\frac{\beta}{1+\beta}\left[\beta\left(\frac{f_{M A X}}{f}\right)+\left(\frac{f}{f_{M A X}}\right)^{\beta}\right]}
$$

where $M_{M A X}^{\prime \prime}$ is the peak value and $\beta$ is the stretching exponent in the range $0 \leq \beta \leq 1$ and indicates the deviation from Debye type relaxation. 
The activation energies $E^{\tau}$, for each glass were determined from the slope of $\log$ vs. $1000 / \mathrm{T}$ using the equation $\tau=\tau_{0} \exp \left(E^{\tau} / k_{B} T\right)$. This Arrhenius type dependence of the relaxation time from which the activation energy was determined is plotted in Fig. 5b. The calculated activation energies are listed in Table 1. The inset in Fig. 4 represents the normalized value of $M_{M A X}^{\prime \prime}$ and frequency is scaled by $f_{\text {MAX }}$ the collapse of data to a master curve is indicative of a common transport mechanism.

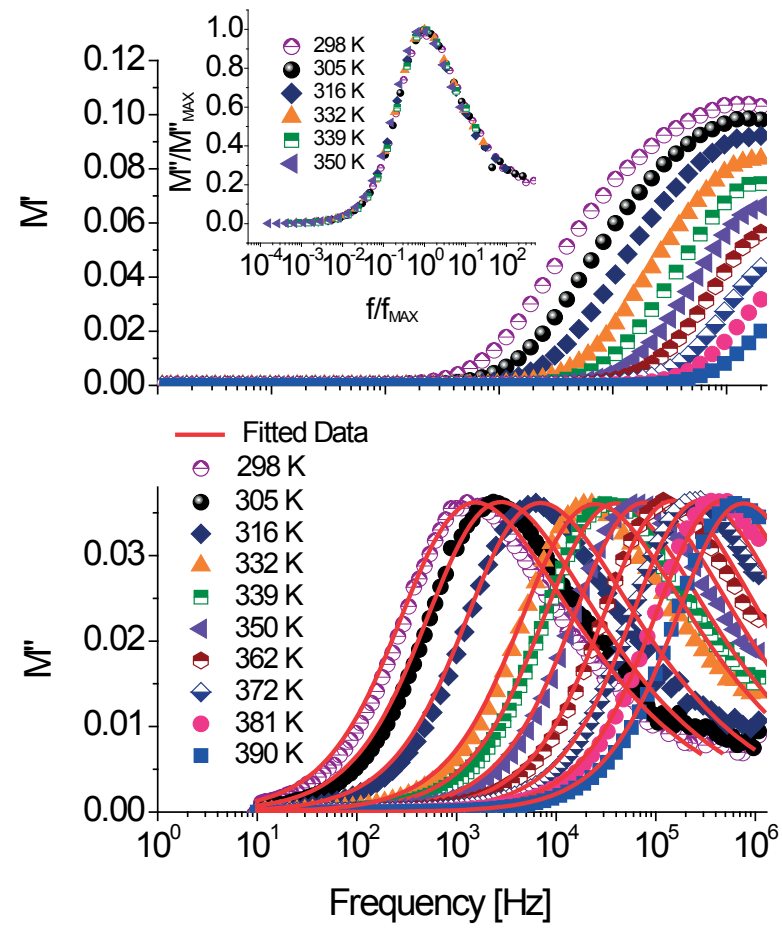

Fig. 4 Imaginary and real representation of frequency dependent modulus; red lines represent the fitted data with $K W W$ function

For the investigated systems Na-B-PO and Li-B-PO, dc conductivities (listed in Table 1) increase with the decrease of the alkali cation radius, i.e. conductivity increases from $\mathrm{Na}$ to $\mathrm{Li}$ containing glasses.
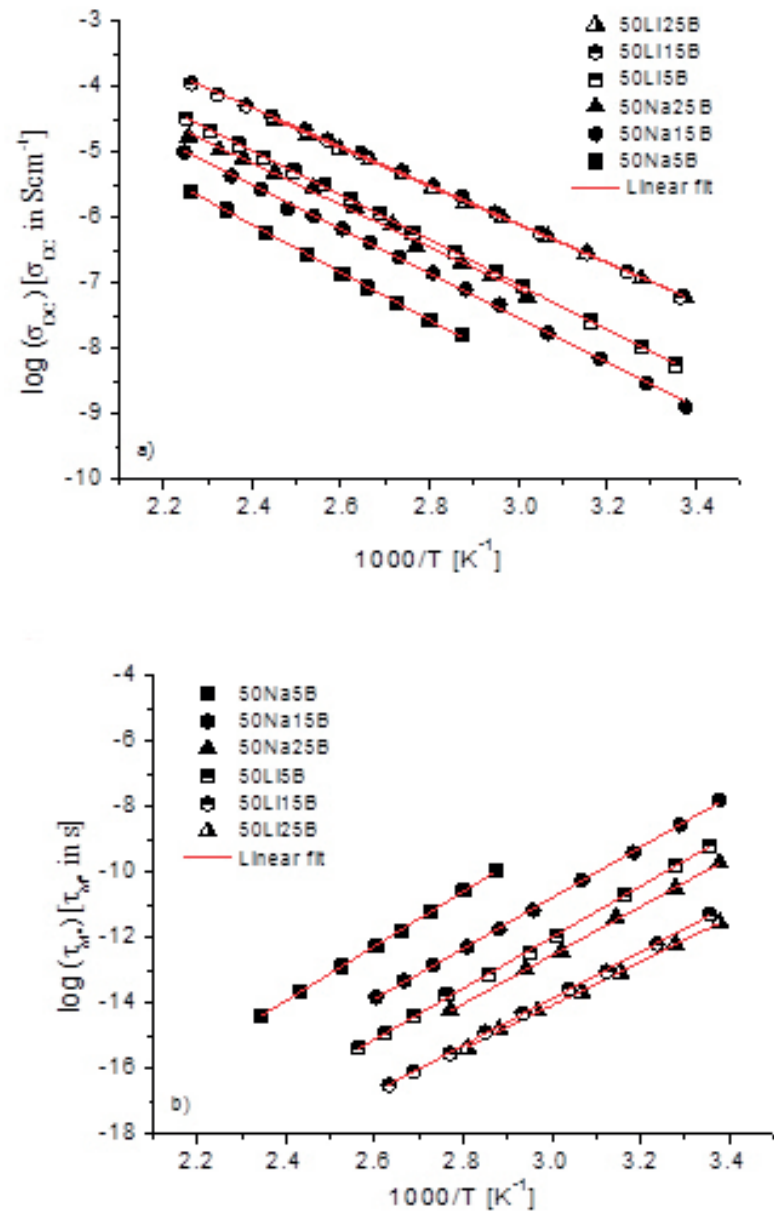

Fig. 5 Arrhenius dependence of $d c$ conductivity a), and relaxation time for conduction $b$ ), depicted for all investigated samples

\section{Conclusions}

The choice of samples $50 \mathrm{Li}_{2} \mathrm{O}-\mathrm{xB}_{2} \mathrm{O}_{3}-\left(50-\mathrm{x}^{-} \mathrm{P}_{2} \mathrm{O}_{5}(\mathrm{x}=5-25\right.$ $\mathrm{mol} \%)$ and $50 \mathrm{Na}_{2} \mathrm{O}-\mathrm{xB}_{2} \mathrm{O}_{3}-(50-\mathrm{x}) \mathrm{P}_{2} \mathrm{O}_{5}(\mathrm{x}=5-25 \mathrm{~mol} \%)$ is due to investigating of the change in ionic conductivity which can be revealed as decrease or increase in the ionic conductivity with

The selected properties of investigated samples $50 \mathrm{R}_{2} \mathrm{O}-\mathrm{xB}_{2} \mathrm{O}_{3}-(50-\mathrm{x}) \mathrm{P}_{2} \mathrm{O}_{5}(\mathrm{x}=5-25 \mathrm{~mol} \%), \mathrm{R}=\mathrm{Li}, \mathrm{Na}$

Table 1

\begin{tabular}{|c|c|c|c|c|c|c|}
\hline Sample & $\begin{array}{c}\mathrm{E}^{\mathrm{DC}} \\
{[ \pm 0.01 \mathrm{eV}]}\end{array}$ & $\begin{array}{c}\sigma_{\mathrm{dc}}{ }^{*} \\
{[\mathrm{~S} / \mathrm{cm}]}\end{array}$ & $\begin{array}{c}\mathbf{E}^{\tau} \\
{[ \pm 0.01 \mathrm{eV}]}\end{array}$ & $\begin{array}{c}\tau^{*} \\
{[\mathrm{~s}]}\end{array}$ & $\mathrm{s}^{*}$ & $\beta^{\Delta}$ \\
\hline $50 \mathrm{Li}^{2} \mathrm{~B}^{*}$ & 0.71 & $2.99 \times 10^{-7}$ & 0.68 & $1.28 \times 10^{-5}$ & 0.82 & $0.51-0.59$ \\
\hline $50 \mathrm{Li} 15 \mathrm{~B}^{*}$ & 0.62 & $2.09 \times 10^{-6}$ & 0.62 & $2.95 \times 10^{-6}$ & 0.9 & $0.52-0.6$ \\
\hline $50 \mathrm{Li} 25 \mathrm{~B}^{*}$ & 0.61 & $1.73 \times 10^{-6}$ & 0.61 & $2.31 \times 10^{-6}$ & 0.91 & $0.53-0.57$ \\
\hline $50 \mathrm{Na} \mathrm{B}^{*}$ & 0.76 & $1.63 \times 10^{-8}$ & 0.72 & $2.96 \times 10^{-4}$ & 0.87 & $0.58-0.65$ \\
\hline $50 \mathrm{Na} 15 \mathrm{~B}^{*}$ & 0.7 & $8.16 \times 10^{-8}$ & 0.67 & $5.98 \times 10^{-5}$ & 0.73 & $0.52-0.59$ \\
\hline $50 \mathrm{Na} 25 \mathrm{~B}^{*}$ & 0.67 & $1.31 \times 10^{-7}$ & 0.64 & $1.45 \times 10^{-5}$ & 0.5 & $0.53-0.57$ \\
\hline
\end{tabular}


the change of glass former substance while keeping the modifier composition constant. The concentration of glass former was in the range from 5 to $25 \mathrm{~mol} \%$ with two types of modifier ions ( $\mathrm{Li}$ and $\mathrm{Na}$ ) that allows us the study of the influence of the structure from the ionic radius point of view. For these two sets, electrical measurements were performed for various temperatures below $\mathrm{T}_{\mathrm{g}}$ and frequency range form $10 \mathrm{~Hz}$ to $2 \mathrm{MHz}$. From conductivity investigation, the value of $\mathrm{dc}$ conductivities and activation energies for conduction were calculated for all samples. De conductivities vary from $2.99 \times 10^{-7} \mathrm{~S} / \mathrm{cm}$ to $1.73 \times 10^{-6} \mathrm{~S} / \mathrm{cm}$ for lithium borophosphate glasses and from $1.63 \times 10^{-8} \mathrm{~S} / \mathrm{cm}$ to $1.31 \times 10^{-7} \mathrm{~S} / \mathrm{cm}$ for sodium borophosphate glasses at $348 \mathrm{~K}$. Furthermore, we can see the increasing character of conductivity with increasing concentration of $\mathrm{B}_{2} \mathrm{O}_{3}$. The activation energy decreases with increasing concentration of $\mathrm{B}_{2} \mathrm{O}_{3}$ in both series of composition, which is in accordance with previous structural studies in alkali borophosphate glasses [7]. The activation energies associated to dielectric loss were estimated from the imaginary part of electric modulus, and the both activation energies are supposed to be activated with similar activation energy.

\section{Acknowledgment}

The authors would like to thank to F. Cernobila for technical assistance. This study was supported by projects VEGA No. 1/0510/17. F. Muñoz thanks funding from project MAT201348246-C2-1-P from Ministerio de Economía y Competitividad (MINECO) of Spain.

\section{References}

[1] YUSUB, S., et al.: Ionic Conductivity, Dielectric and Optical Properties of Lithium Lead Borophosphate Glasses Combined with Manganese Ions. Journal of Alloys and Compounds, 663, 708-717, 2016.

[2] CHRISTENSEN, R., et al.: Ionic Conductivity of Mixed Glass Former $0.35 \mathrm{Na}_{2} \mathrm{O}+0.65\left[\mathrm{xB}_{2} \mathrm{O}_{3}+(1-\mathrm{x}) \mathrm{P}_{2} \mathrm{O}_{5}\right]$ Glasses. Journal of Physical Chemistry B, 117, 16577-16586, 2013.

[3] THO, T. D., et al.: Structure Property Correlation in Lithium Borophosphate Glasses. European Physical Journal E, 35(8), 2012.

[4] YOON, Y., et al.: Characterization of Lithium Borophosphate Glass thin Film Electrolytes Deposited by FR-magnetron Sputtering for Mico-batteries. Solid State Ionics, 225, 636-640, 2012.

[5] NISHIKAWA, K., et al. Lidendrite Growth and Li+ Ionic Mass Transfer Phenomenom. Journal of Electroanalytical Chemistry, 661, 84-89, 2011

[6] KUMAR, S., et al.: Investigations of Structure and Transport in Lithium and Silver Borophosphate Glasses. Journal of Solid State Chemistry, 177, 1723-1737, 2004.

[7] MUNOZ, F., et al.: Composition and Structure Dependence of the Properties of Lithium Borophosphate Glasses Showing Boron Anomaly. Journal of Non-Crystalline Solids, 355, 2571-2577, 2009.

[8] MOGUS-MILANKOVIC, A., et al.: Lithium-Ion Mobility in Quaternary Boro-Germano-Phosphate Glasses. Journal of Physical Chemistry, 120, 3978-3987, 2016.

[9] MAGISTRIS, A., et al.: Lithium Borophosphate Vitreous Electrolytes. Journal of Power Sources, 14, 87-91, 1985.

[10] JONSCHER, A. K.: The Universal Dielectric Response. Annual Conference on Electrical Insulation and Dielectric Phenomena, USA, 23-40, 1990.

[11] HOCKICKO, P., et al.: Investigation of Acoustic and Electrical Properties of a $\mathrm{LiPO}_{3}$ Metaphosphate Glass. CommunicationsScientific Letters of the University of Zilina, 16(1), 45-49, 2014.

[12] KUDELCIK, J., et al.: The Dielectric Breakdown of Magnetic Fluids. Communications- Scientific Letters of the University of Zilina, 12(2), 34-37, 2010.

[13] MEENAKSHI, D., et al.: Temperature and frequency dependent conductivity and electric modulus formulation of manganese modified bismuth silicate glasses. Journal of NonCrystalline Solids, 423-424, 1-8, 2015. 